\title{
Lung-Centered Open Heart Surgery: A Call for a Paradigm Change
}

\author{
Edward Gologorsky ${ }^{1 *}$, Angela Gologorsky ${ }^{2}$ and Tomas Antonio Salerno ${ }^{3}$ \\ ${ }^{1}$ Anesthesiology, Allegheny General Hospital, Pittsburgh, PA, USA, ${ }^{2}$ Anesthesiology, Private Practice, Miami Beach, FL, USA, \\ ${ }^{3}$ Cardiovascular Surgery, University of Miami Miller School of Medicine, Miami, FL, USA
}

Keywords: cardiopulmonary bypass, postoperative complications, pulmonary dysfunction, capnography, ischemia-reperfusion injury

"The time has come," in the famous words of Lewis Carroll, "to talk of many things," and we would like to talk about many things that lead to severe pulmonary dysfunction after cardiac surgery. The term is broad indeed and is usually taken to represent a wide gamut ranging from well-compensated abnormalities of respiratory mechanics to symptomatic hypoxemia secondary to ventilation/perfusion mismatching to more significant prolonged ventilator dependency to dreaded "respiratory cripple." Overwhelming financial and societal costs aside, prolonged ventilator dependency carries the staggering in-house mortality in excess of $40 \%$ (1). The incidence and severity was reported to vary widely between centers, partially because of disparate definitions, but significantly because of poorly defined "hospital quality" characteristics $(2,3)$. We agree with those who look for the causes outside the various demographic characteristics, but rather focus on performance, perioperative surgical and anesthetic techniques, experience and expertise of surgical perioperative care team $(4,5)$. Let us concentrate on what we actually do in the operating room and see what can be improved.

Let us follow, in broad strokes, what happens to the lungs in the course of a traditional intraoperative care of a patient presenting for an open heart surgery. To start, the lungs are ventilated with $\mathrm{F}_{\mathrm{i}} \mathrm{O}_{2}=1.0$, large tidal volumes, and zero end-expiratory pressure until the extracorporeal circulation is established. At that moment the mechanical ventilation is completely suspended, with resultant profound iatrogenic atelectasis. Concurrently, as venous return is diverted into cardiopulmonary bypass (CPB) circuit, pulmonary arterial flow ceases, rendering lungs dependent on bronchial arterial flow. The latter, normally approximately $10 \%$ of the nutrient flow, is highly variable during the bypass period as it is determined by systemic pressures and flows. Thus, ischemic and atelectatic organ, subjected to oxygen toxicity and ventilator-induced injury during pre-bypass period, is now exposed to CPB-induced systemic inflammatory response (SIRS), greatly potentiated by sequestration of activated polymorphonuclear leukocytes in pulmonary capillaries. After completion of CPB, the lungs are again subjected to repeated stretch trauma of "bag squeezing" recruitment maneuvers, and face additional injury due to reperfusion, potentiated by reactive oxygen species in hyperoxic $\left(\mathrm{F}_{\mathrm{i}} \mathrm{O}_{2}=1.0\right)$ milieu. Additionally, the right ventricular performance may be impaired in the early post-bypass period due to cardioplegia-induced edema and swelling, regional tissue electrolyte, metabolic and temperature heterogeneity, and ischemia-reperfusion injury (silent ischemia is common and is frequently undetected in a quiescent myocardium). Note that protamine administration typically takes place during the early reperfusion period of both lungs and myocardium; we believe that hemodynamic manifestations of ARDS-like pulmonary injury and RV dysfunction greatly potentiate the so-called "protamine reaction."

"Vision," Jonathan Swift remarked, "is the art of seeing things invisible." Akin to an iceberg, lung injury during cardiac surgery is a process clinically significant in only a minority of patients. But we know that it takes place in all patients, and though frequently undetected and unsuspected, may be devastating when manifested. Patient descriptors usually associated with prolonged ventilator dependency after cardiac surgery, such as age, emphysema, heart failure, renal failure, prolonged $\mathrm{CPB}$, complex procedures, and significant transfusion requirements, can all be understood as

Gologorsky E, Gologorsky A ar Salerno TA (2016) Lung-Centered Open Heart Surgery: A Call for a Paradigm Change. 
pathologic preconditions that, to the degree that they exhaust the adaptive compensatory mechanisms, greatly potentiate the noxious effects of pulmonary volutrauma, atelectrauma, biotrauma, and ischemia-reperfusion injury in hyperoxic and inflammatory milieu, allowing the ARDS-like syndrome to be manifested earlier and more severe.

Insanity is said to be "doing the same thing over and over again, and expecting different results." So what could be done differently for patients at risk for postoperative pulmonary dysfunction? We advocate lung-centered paradigm of intraoperative management of a cardiac surgical patient. Changes are needed both in anesthetic management and in surgical gestalt. In addition to numerous improvements in $\mathrm{CPB}$ circuit design and perfusion techniques geared toward lessening the inflammatory response (5-7), we specifically advocate adoption of protective pulmonary ventilation and concurrent continuous pulmonary perfusion and ventilation throughout the $\mathrm{CPB}$ period.

Despite being introduced into general clinical practice more than a decade ago, protective pulmonary ventilation in cardiac surgery is still not routine (8). This concept includes ventilating with lower tidal volumes, and advocates titrated positive end-expiratory pressure (PEEP) and recruitment maneuvers to maintain patency of alveoli and lower $\mathrm{F}_{\mathrm{i}} \mathrm{O}_{2}$ to avoid oxygen toxicity and absorption atelectasis while maintaining acceptable oxyhemoglobin saturations $(9,10)$. Once initiated with induction of general anesthesia, it should be continued throughout the entire perioperative period including intensive care unit (ICU). We suspect that its implementation in cardiac surgery has been hampered by the apprehension of its futility in the face of induced prolonged iatrogenic atelectasis and pulmonary ischemia, concerns regarding the effects of PEEP on RV function, and traditional reliance on high $\mathrm{FiO}_{2}$ to mask the resultant hypoxemia. However, maintaining protective pulmonary ventilation during the bypass period would address all of these concerns. In fact, some preliminary data suggest improved patients' outcomes with mitigated ventilator-induced injury and atelectrauma in both off-pump on on-pump cardiac surgery $(11,12)$.

\section{REFERENCES}

1. Trouillet JL, Combes A, Vaissier E, Luyt CE, Ouattara A, Pavie A, et al. Prolonged mechanical ventilation after cardiac surgery: outcome and predictors. J Thorac Cardiovasc Surg (2009) 138(4):948-53. doi:10.1016/j. jtcvs.2009.05.034

2. Rangrass G, Ghaferi AA, Dimick JB. Explaining racial disparities in outcomes after cardiac surgery: the role of hospital quality. JAMA Surg (2014) 149(3):223-7. doi:10.1001/jamasurg.2013.4041

3. Khandelwal N, Dale CR, Benkeser DC, Joffe AM, Yanez ND, Treggiari MM. Variation in tracheal reintubations among patients undergoing cardiac surgery across Washington state hospitals. J Cardiothorac Vasc Anesth (2015) 29(3):551-9. doi:10.1053/j.jvca.2014.11.009

4. Glance LG, Kellermann AL, Hannan EL, Fleisher LA, Eaton MP, Dutton RP, et al. The impact of anesthesiologists on coronary artery bypass graft surgery outcomes. Anesth Analg (2015) 120(3):526-33. doi:10.1213/ ANE.0000000000000522

5. Knapic P, Ciesla D, Borowik D, Czempik P, Knapic T. Prolonged ventilation post cardiac surgery - tips and pitfalls of the prediction game. J Cardiothorac Surg (2011) 6:158. doi:10.1186/1749-8090-6-158
So why did some earlier studies of pulmonary ventilation during bypass not find a significant effect on postoperative pulmonary function? (13). We believe that the absence of simultaneous pulmonary perfusion in these studies provides the answer (14). Ventilating ischemic alveoli is not likely to be of any lasting benefit, just as perfusing atelectatic lungs may exacerbate the alveolar edema and would be of questionable value. Despite some enthusiastic reports describing the benefits of isolated pulmonary perfusion (15-17), we insist that to be clinically significant, pulmonary perfusion should be matched with pulmonary ventilation. While the details and the specifics of the technique of pulmonary perfusion during bypass period still await further studies, in our practice, we use a $3-\mathrm{mm}$ cannula connected to the port of the aortic cannula to perfuse the pulmonary artery with arterial blood. Simultaneous capnography provides the key to this technique, as observation of end-tidal $\mathrm{CO}_{2}$ waveform provides a continuous, reliable, and reproducible evidence of alveolar perfusion and ventilation (18).

It is highly probable that simultaneous pulmonary perfusion and pulmonary protective ventilation may not only mitigate the noxious effect of ventilator trauma, atelectasis, and ischemiareperfusion injury, but may also prevent bacterial translocation and diminish SIRS, as reported by Richter et al. using the DrewAnderson technique (19). Therefore, the question arises - what will it take to make continuous protective pulmonary ventilation and pulmonary perfusion on bypass a reality in cardiac surgery? We believe that patients at the highest risk for postoperative pulmonary complications and ventilator dependency would benefit the most from a lungs-centered approach, conceptually comparable to the perfusion-supported beating-heart technique in high-risk heart failure patients $(18,20)$. The time has come to put the vulnerable target organs into primary focus.

\section{AUTHOR CONTRIBUTIONS}

EG, AG, and TS contributed to the manuscript and reviewed the manuscript.

6. Apostolakis EE, Koletsis EN, Baikoussis NG, Siminelakis SN, Papadopoulos GS. Strategies to prevent intraoperative lung injury during cardiopulmonary bypass. J Cardiothorac Surg (2010) 11(5):1. doi:10.1186/1749-8090-5-1

7. Badenes R, Lozano A, Belda FJ. Postoperative pulmonary dysfunction and mechanical ventilation in cardiac surgery. Crit Care Res Pract (2015) 2015:420513. doi:10.1155/2015/420513

8. Romagnoli S, Ricci Z. Lung protective ventilation in cardiac surgery. Heart Lung Vessels (2015) 7(1):5-6.

9. Neto AS, Simonis FD, Barbas CS, Biehl M, Determann RM, Elmer J, et al. Lung-protective ventilation with low tidal volumes and the occurrence of pulmonary complications in patients without acute respiratory distress syndrome: a systematic review and individual patient data analysis. Crit Care Med (2015) 43(10):2155-63. doi:10.1097/ CCM.0000000000001189

10. Güldner A, Kiss T, Serpa Neto A, Hemmes SN, Canet J, Spieth PM, et al. Intraoperative protective mechanical ventilation for prevention of postoperative pulmonary complications: a comprehensive review of the role of tidal volume, positive end-expiratory pressure, and lung recruitment maneuvers. Anesthesiology (2015) 123(3):692-713. doi:10.1097/ ALN.0000000000000754 
11. John LCH, Ervine IM. A study assessing the potential benefit of continued ventilation during cardiopulmonary bypass. Interact Cardiovasc Thorac Surg (2008) 7:14-7. doi:10.1510/icvts.2007.158451

12. Bolzan DW, Trimer R, Begot I, Nasrala ML, Forestieri P, Mendez VM, et al. Open-lung ventilation improves clinical outcomes in off-pump coronary artery bypass surgery: a randomized controlled trial. J Cardiothorac Vasc Anesth (2015). doi:10.1053/j.jvca.2015.09.001

13. Schreiber JU, Lance MD, De Korte M, Artmann T, Aleksic I, Kranke P. The effect of different lung-protective strategies in patients during cardiopulmonary bypass: a meta-analysis and semiquantitative review of randomized trials. JCardiothorac Vasc Anesth (2012) 26(3):448-54. doi:10.1053/j. jvca.2012.01.034

14. Salerno TA, Macedo FI, Gologorsky E. Pulmonary ventilation should be matched with pulmonary perfusion during cardiopulmonary bypass. J Cardiothorac Vasc Anesth (2012) 26(5):e60. doi:10.1053/j.jvca.2012.04.014

15. Gabriel EA, Fagionato Locali R, Katsumi Matsuoka P, Santiago Almeida L, Guerreiro Silva I, Capelozzi VL, et al. Lung perfusion during cardiac surgery with cardiopulmonary bypass: is it necessary? Interact Cardiovasc Thorac Surg (2008) 7(6):1089-95. doi:10.1510/icvts.2008.184275

16. Suzuki T. Additional lung-protective perfusion techniques during cardiopulmonary bypass. Ann Thorac Cardiovasc Surg (2010) 16(3):150-5.

17. Suzuki T, Fukuda T, Ito T, Inoue Y, Cho Y, Kashima I. Continuous pulmonary perfusion during cardiopulmonary bypass prevents lung injury in infants. Ann Thorac Surg (2000) 69(2):602-6. doi:10.1016/S0003-4975(99)01332-6
18. Macedo FI, Gologorsky E, Costa AC, Pham SM, Salerno TA. Beating heart surgery with pulmonary perfusion and ventilation during cardiopulmonary bypass: target organs' perfusion without plegia. Semin Thorac Cardiovasc Surg (2012) 24(4):308-10. doi:10.1053/j.semtcvs.2012.08.002

19. Richter JA, Meisner H, Tassani P, Barankay A, Dietrich W, Braun SL. Drew-Anderson technique attenuates systemic inflammatory response syndrome and improves respiratory function after coronary artery bypass grafting. Ann Thorac Surg (2000) 69(1):77-83. doi:10.1016/ S0003-4975(99)01131-5

20. Erkut B, Dag O, Kaygin MA, Senocak M, Limandal HK, Arslan U, et al. On-pump beating-heart versus conventional coronary artery bypass grafting for revascularization in patients with severe left ventricular dysfunction: early outcomes. Can J Surg (2013) 56(6):398-404. doi:10.1503/cjs.018412

Conflict of Interest Statement: The authors declare that the research was conducted in the absence of any commercial or financial relationships that could be construed as a potential conflict of interest.

Copyright (C) 2016 Gologorsky, Gologorsky and Salerno. This is an open-access article distributed under the terms of the Creative Commons Attribution License (CC BY). The use, distribution or reproduction in other forums is permitted, provided the original author(s) or licensor are credited and that the original publication in this journal is cited, in accordance with accepted academic practice. No use, distribution or reproduction is permitted which does not comply with these terms. 